\title{
Erratum to: Comparative transcriptomics reveals the conserved building blocks involved in parallel evolution of diverse phenotypic traits in ants
}

Claire Morandin ${ }^{1,2^{*}}$, Mandy M. Y. Tin ${ }^{3}$, Sílvia Abril ${ }^{4}$, Crisanto Gómez ${ }^{4}$, Luigi Pontieri ${ }^{5}$, Morten Schiøtt ${ }^{5}$, Liselotte Sundstrom ${ }^{1,2}$, Kazuki Tsuji ${ }^{6}$, Jes Søe Pedersen ${ }^{5}$, Heikki Helantera ${ }^{1,2}$ and Alexander S. Mikheyev ${ }^{3,7^{*}}$

\section{Erratum}

After the publication of this work [1] it was noticed that the mapping between column 1 and 2 in the Additional file 7 - Table S5 was incorrect.

Please see the corrected additional file below.

The publisher apologises for this error.

\section{Additional file}

Additional file 7: Table S5. List of blast annotations for each OGG

using BLASTp. (XLSX $222 \mathrm{~kb})$

\begin{abstract}
Author details
${ }^{1}$ Centre of Excellence in Biological Interactions, Department of Biological and Environmental Sciences, University of Helsinki, Helsinki, Finland. ${ }^{2}$ Tvärminne Zoological Station, University of Helsinki, J.A. Palménin tie 260, Fl-10900 Hanko, Finland. ${ }^{3}$ Okinawa Institute of Science and Technology, 1919-1 Tancha Onna-son, Kunigami-gun, Okinawa 904-0412, Japan. ${ }^{4}$ Department of Environmental Sciences, University of Girona, Campus Montilivi, 17071 Girona, Spain. ${ }^{5}$ Centre for Social Evolution, Department of Biology, University of Copenhagen, Universitetsparken 15, DK-2100 Copenhagen, Denmark. ${ }^{6}$ Department of Subtropical Agro-Environmental Sciences, University of the Ryukyus, Senbaru 1, Nishihara, Okinawa 903-0213, Japan. ${ }^{7}$ Research School of Biology, Australian National University, Canberra ACT 0200, Australia.
\end{abstract}

Received: 18 August 2016 Accepted: 18 August 2016

Published online: 25 August 2016

\section{Reference}

1. Morandin C, Tin MMY, Abril S, Gomez C, Pontieri L, Schiøtt M, et al. Comparative transcriptomics reveals the conserved building blocks involved in parallel evolution of diverse phenotypic traits in ants. Genome Biol. 2016;17:43.

\footnotetext{
* Correspondence: claire.morandin@helsinki.fi; sasha@homologo.us ${ }^{1}$ Centre of Excellence in Biological Interactions, Department of Biological and Environmental Sciences, University of Helsinki, Helsinki, Finland

${ }^{3}$ Okinawa Institute of Science and Technology, 1919-1 Tancha Onna-son, Kunigami-gun, Okinawa 904-0412, Japan

Full list of author information is available at the end of the article
}

Submit your next manuscript to BioMed Central and we will help you at every step:

- We accept pre-submission inquiries

- Our selector tool helps you to find the most relevant journal

- We provide round the clock customer support

- Convenient online submission

- Thorough peer review

- Inclusion in PubMed and all major indexing services

- Maximum visibility for your research

Submit your manuscript at www.biomedcentral.com/submit 